\title{
Virtual social networks and mental health intervention for medical staff during the COVID-19 outbreak in the Islamic Republic of Iran
}

Maryam Zaare Nahandi, ${ }^{1}$ Hassan Shahrokhi, ${ }^{2}$ Sara Farhang ${ }^{2,4}$ and Mohammad Hossein Somi ${ }^{3}$

${ }^{1}$ Department of Internal Medicine, Faculty of Medicine, Tabriz University of Medical Sciences, Tabriz, Islamic Republic of Iran. ${ }^{2}$ Research Center of Psychiatry and Behavioral Sciences, Tabriz University of Medical Sciences, Tabriz, Islamic Republic of Iran. ${ }^{3} \mathrm{Liver}$ and Gastrointestinal Diseases Research Center, Tabriz University of Medical Sciences, Tabriz, Islamic Republic of Iran. ${ }^{4}$ University of Groningen, University medical center Groningen, University Center for Psychiatry, Rob Giel research center, Groningen. The Netherlands. (Correspondence to: Sara Farhang: dsfarhang@gmail.com).

Citation: Nahandi MZ; Shahrokhi H; Farhang S; Somi MH. Virtual social networks and mental health intervention for medical staff during the COVID-19 outbreak in the Islamic Republic of Iran. East Mediterr Health J. 2020;26(5):497-498. https://doi.org/10.26719/2020.26.5.497

Received: 13/03/20; accepted: 21/04/20

Copyright (c) World Health Organization (WHO) 2020. Open Access. Some rights reserved. This work is available under the CC BY-NC-SA 3.o IGO license (https://creativecommons.org/licenses/by-nc-sa/3.o/igo).

Previous experiences from other crises have confirmed that timely mental health intervention is critical for medical staff caring for patients, in this case those affected by COVID-19 (1). Negative emotions and stress can originate from fear of infection, isolated working conditions, fear of transmission to family or friends, and increased workload. Social contacts potentially increase the risk of contamination and should be restricted, resulting in people losing the benefits of social interaction. Behaviours that were considered potentially 'pathological' by mental health care providers during any other crisis are now being tolerated in the current COVID19 situation. Thus, decreased levels of self-confidence in health care providers in all of disciplines and higher stress levels are apparent (2). Consequently, such frontline medical staff want help. However, the ensuing overload of information is not always reproductive and can lead to higher levels of anxiety.

Medical professionals working in the Islamic Republic of Iran are facing even more challenges compared to their colleagues in other countries when it comes to social support (3). First, there have been several tragic events that have happened recently in the country (natural disasters, passenger aircraft crash) as well as continuing international political tensions. Second, American economic sanctions continue to affect the availability of essential medicines and equipment. Third, cultural and religious gatherings in the Islamic Republic of Iran might increase the risk of the spread of communicable diseases.

Given this background, finding a replacement for social contact is paramount. While there is still a long way to establish tele-medicine in the Islamic Republic of Iran, social networking remains popular in the country (4). When considering the social restrictions imposed as a result of the efficiency of COVID19 transmission, virtual social networking might be the best replacement for traditional face-to-face psychological interventions.

Tabriz University of Medical Sciences has implemented activities to address this need. Psychological intervention teams have been set up by the university's Department of Psychiatry to coordinate and manage the operation. Based on the conduct of group therapy, small groups have been established using social networking applications, organized by two supervisors in each group. Information is provided only to answer the direct needs of participants and information overload is deliberately avoided. Participants are encouraged to describe their daily experiences followed by relevant and directed discussions, and the groups are effectively participantled, with supervisor facilitation.

In addition, an online platform has been established to screen for those who need a more thorough psychiatric intervention and addresses excessive levels of stress, anxiety and depression. Coupled with this platform is telephone guidance to help deal with mental health problems that care givers might be experiencing as a result of the current COVID19 situation.

Despite these support interventions, mental health care for health professionals is still not a consideration in Iranian national guidelines on COVID-19. While adequate medical resources will bring some sense of support, it remains clear that communication and accurate updates about the coronavirus outbreak will decrease the sense of uncertainty, while adequate health care support will assure quality of care and decrease workload. Thus, revised and focused guidelines are fundamental in the current situation.

\section{Acknowledgement}

Authors would like to thank Sina Educational, Reach and treatment Center. 


\section{References}

1. Xiang YT, Yang Y, Li W, Zhang L, Zhang Q, Cheung T, et al. Timely mental health care for the 2019 novel coronavirus outbreak is urgently needed. Lancet Psychiat. 2020 Feb 4.

2. Chen Q, Liang M, Li Y, Guo J, Fei D, Wang L, et al. Mental health care for medical staff in China during the COVID-19 outbreak. Lancet Psychiat. 2020 Feb 19.

3. Ariapooran S. Compassion fatigue and burnout in Iranian nurses: The role of perceived social support. Iran J Nurs Midwifrey Res. 2014 May;19(3):279.

4. Salehahmadi Z, Hajialiasghari F. Telemedicine in Iran: chances and challenges. World J Plast Surg. 2013 Jan;2(1):18. 